\section{Confounding in epidemiological studies}

EdrTor,--George Davey Smith and Andrew N Phillips draw attention to the problems of confounding, especially residual confounding, in epidemiological studies.' This is poorly understood and has led to many serious misunderstandings. It should always be considered as an explanation of any epidemiological association, but in some cases observational studies cannot resolve the issue, and one should not conclude that possibly confounded exposures should be ignored. When this impasse is reached it may be more appropriate to consider intervention studies.

The example of smoking and cervical cancer is a case in point. Early observations of this association were played down because of possible confounding with sexual behaviour. The relation was not, however, weakened when attempts were made to adjust more carefully for this-a procedure that often indicates residual confounding-and now dozens of carefully designed studies have found a strong relation. Clearly, randomising young women to smoke or not would be both ridiculous and unethical. We are attempting to study the effects of stopping smoking on untreated but carefully monitored mild cervical disease, with reference to both clinical and immunological variables. Studies of this kind may prove useful in resolving the problems of counfounding.

IACK CU\%ICK ANNE: SZAREWSKI

\section{Imperial Cancer Research Fund,}

London $\mathrm{W}^{2} \mathrm{C} 2 \mathrm{~A} 3 \mathrm{PX}$

1 Davey Smith G, Phillips AN. Counfounding in epidemiological studies: why "independent" effects mav not be all they seem. studies: why independent effects ma'

EDIToR,--George Davey Smith and Andrew N Phillips lay into our fellow epidemiologists with gusto, but in their zeal to preserve us from false hopes of aetiological discovery and so of prevention they may have overreacted in the case of at least one of their prime examples.

Lack of physical activity, they say, is related to obesity (presumably they intend overweight); "obesity" is a powerful risk factor in its own right for diabetes (presumably they intend non-insulin dependent diabetes); ergo, the relation of lack of physical activity to the incidence of diabetes--now shown in prospective studies of three different populations and using two different methods of assessing physical activity ${ }^{2-1}$ could be due merely to confounding with obesity. Several points may be made.

Overweight and lack of physical activity are indeed closely and complexly interrelated. For example, a common route to weight gain in middle age is failure to adjust energy intake to declining energy output. Which component is effective "in its own right" and which doesn't matter? How much "lack of physical activity" does obesity contain? And so on.

In studies of non-insulin dependent diabetes in men the greatest reduction of incidence with physical activity occurred in the heaviest subjects, scarcely to be expected on a null hypothesis. Imprecision in self assessment of height and weight could of course be material even in University of Pennsylvania male graduates,- American women nurses,' and American male physicians, ' who were surveyed, but would it be imprecise enough to wipe out such trends? It would be worth demonstrating. A check in the study of nurses was reassuring.

Moreover, in the studies of doctors and nurses (but not the graduates) total estimates of energy output, so relevant to body weight, were not analysed. Instead their index was the report of vigorous exercise long enough to work up a sweat. (Vigorous sports were also the most protective in the study of graduates.) Such vigorous exercise could be activating other physiological mechanisms of possible protection than those of energy balance.

The point that Davey Smith and Phillips raise about "biological plausibility" is well taken. Too often there is a whiff of circular argument when this is deployed. Be that as it may, after 20 years" of repeated observations that exercise favourably affects glucose tolerance and insulin resistance, what would really have been interesting is a failure to show some protection by exercise against the occurrence of non-insulin dependent diabetes. This protection is estimated as "at least 25 per cent" from the American physicians study.

In short, the evidence of lower incidence of noninsulin dependent diabetes with exercise surely stands, one of considerable promise in so serious and common a disease, $5 \%$ of our (European) population over 40 years of age

JNMORRIS

Health Promotion Sciences L'nit,

Lendon School of Hygienc

and Tropical Medicin

I. ondon W'C1E $7 \mathrm{H}$

1 Davey Smith G, Phillips AN. Confounding in epidemiological studies: why "independent" effects may not be all they seem. BMI 1992:305:757-9. (26 September.

2 Heimrich SP, Ragland DR, Leung AB, Paffenbarger RS Physical activity and reduced occurrence of non-insulin dependent diabetes mellitus. $\times$ Engl F. Mked 1991:325:14i-52.

3 . Manson JE. Rimm EB, Stampfer MJ, Colditz (iA, Willett WC, Knowleski AS, it al. Physical activity and incidence of noninsulin dependent diabetes mellitus in women. Lancit 1991 338: $774-8$.

4 Manson JE, Nathan 1)M, Knowleski AS, Stampfer MJ, Willet WC C, Hennekens CH. A prospective study of exercise and incidence of diabctes among US male phrsicians. $\not A M A$ incidence of

5 Morris JN, Clayton DG, Everitt MG, Semmence A.M, Burgess EH. Exercise in leisure time: coronary attack and death rates Br Heart f 1990;63:325-34.

6 Bjorntorp P, Fahlen .1. Grimby G. Carbohydrate and lipic metabolism in well-trained men. Mctubolism 1972;21:1037-44

7 McKeigue PM, Shah B, Marmot MG. Relation of central obesity and insulin resistance with high diabetes prevalence an cardievascular risk in south Asians. Lancet 1991;337:382-6.

\section{Large volume plastic spacers}

EDTTOR,-I wish to add a further comment on the use of large volume plastic spacers, discussed by Duncan Keeley.' In our genitourinary medicine clinics we frequently see patients who are taking inhaled pentamidine monthly as prophylaxis against pneumocystis pneumonia and always use a bronchodilator before the inhalation treatment. A the patients are being treated only once a month they do not become adept at using the pressurised aerosol inhalers, and instructing them on how to use one at each return visit can be time consuming. We now use the large volume plastic spacers and have found a considerable improvement. Showing patients how to use them is simple, and a lot of instruction time is saved. We can be confident of adequate bronchodilatation before treatment. Moreover, the patients feel more relaxed about coming to the clinic for their treatment knowing that they are not going to have to perform an intricate coordination manoeuvre. A spacer is labelled with the patient's name and number and kept for his or her use only.

Adequate bronchodilatation may also reduce the likelihood of coughing during the pentamidine treatment. This may be important, particularly as Fischl et al recently reported transmission of tuberculosis among HIV positive patients attending clinics in the United States and implicated inhalation treatment as one environmenta factor that may have contributed to an outbreak.
Keeley D. Iarge volume plastic spacers in asthma. B.117 1992:305:598-9. (12 September.

Fischl MA, Uttamchandani RB, Daikos GL, Poblete RB, Moreno JN, Reves RR, it al. An outbreak of tuberculosis caused by , Reyes RR, ct al. An outbreak of tuberculosis infection. Amin Intern Med 1992;117:177-83.

\section{Poor training in rheumatology}

EDrTor,--Philip Steadman is concerned about disabled people not applying for the disability living allowance because of their fears of a medical examination.' In Arthritis Care's experience the reason for this and similar problems for example, with applications for orange badges (indicating disability) and arranging transport to hospital--is the poor understanding of arthritis among many general practitioners.

General practitioners spend little time on rheumatology during their training, and they often seem not to understand the problems of people with arthritis. Many members of Arthritis Care tell us that their general practitioners do not appreciate how much the pain and mobility in arthritis vary from day to day and how much damage can be caused to affected joints by inappropriate walking or, indeed, by sitting in the same position for long periods. A person who seems to be able to walk quite well one day may barely be able to get out of bed the next. Arthritis Care would be grateful for the BMA's support in its efforts to improve medical education in rheumatology and arthritis.

Arthritis Care, REGUTCH

London NW1 $12 \mathrm{HD}$

Steadman P. Applving for disability living allowance. BMY 1992;305:893. (10 October.)

\section{Assisted conception for infertility}

Entror,--M G R Hull and colleagues have obtained excellent results in their assisted conception programme.' In our view, however, their expectations of assisted conception for infertility are not realistic.

A critical factor in the calculation of the KaplanMeier curve for estimating cumulative pregnancy rates--rhe method the authors used-is the assumption that couples who stop treatment after the first or following cycles will have had the same chance of conceiving by assisted conception as couples who continue treatment. From the data presented it is impossible to conclude whether this assumption is met, and the authors do not indicate whether they are aware of this methodological trap. Couples who do not become pregnant but decide to continue treatment in the next cycle may well represent selection of more favourable cases.

To analyse this we studied all couples who participated in our in vitro fertilisation programme from 1985 until 1990 for a first $(n=525)$, second $(n=309)$, third $(n=190)$, and fourth $(n=100)$ attempt at in vitro fertilisation. After each cycle three groups were distinguished: couples who achieved a pregnancy, couples who did not achieve a pregnancy and.continued treatment in another cycle, and couples who did not achieve a pregnancy and decided to stop treatment. We analysed the second and third groups, looking at some factors of potential prognostic importance: a favourable indication (tubal factor or unexplained infertility) or unfavourable indication (male factor) for in vitro fertilisation, total fertilisation failure, fertilisation rate, and age of the woman. Continuous data were analysed by analysis of variance and the discrete data by the Mantel-Haenszel $\chi^{2}$ test.

The differences between the couples who stopped and who continued treatment were significant for total fertilisation failure $(p=0.0008)$ 